\title{
LA RECEPCIÓN DE LOS CLÁSICOS EN LAS CONCEPCIONES DE JUAN EGAÑA ACERCA DEL ARTE (1768-1836)
}

Reception of Egaña's conception of the arts classics (1768-1836)

\author{
Fernando Guzmán Schiappacasse* \\ Eugenio Yáñez Rojas**
}

\section{Resumen}

El jurista chileno Juan Egaña manifestó en sus acciones y en sus escritos una especial valoración por las expresiones artísticas. Para el autor las normas jurídicas y el arte deben articularse y apuntar a un mismo objetivo. El presente trabajo se orienta a mostrar los fundamentos que permiten afirmar que, en sintonía con las concepciones de Platón, Egaña concibió la pintura, la escultura, la música y la arquitectura al servicio de la organización de la sociedad.

Palabras clave: Arte, Política, Chile, Platón.

Abstract

The chilean attorney Juan Egaña showed in his actions and essays a special interest in artistic expressions. Art and the juridical norms must work together and point to a same objective. This article is oriented to show the essentials that confirm that following ideas of Plato, Egaña conceived painting, sculpture, music and architecture put to the service of the organization of the society.

Key words: Arts, Politics, Chile, Platon.

\section{INTRODUCCIÓN}

Las elites que lideraron el proceso de independencia en Hispanoamérica debieron enfrentar desafíos tan complejos como legitimar a los nuevos gobernantes o formular un proyecto de nación convincente. Para la consecución de ambos objetivos se sirvieron de diversos medios, entre estos los que ofrecía el arte, la arquitectura y los rituales. Era necesario, por ejemplo, dotar a las autoridades forjadas en el fragor de la revolución de un aparato simbólico que reemplazara eficazmente el boato de la monarquía, así como también era indispensable — en palabras de Anthony Smith - trazar un proyecto común y exteriorizarlo por medio de imágenes eficaces y estimulantes (102).

La cultura barroca había dado lugar a una estrecha relación entre el arte y la política; en la América de los siglos XVII y XVIII — al igual que en Europa - era habitual el uso de la pintura, la escultura y los edificios como herramientas de propaganda política. Sin embargo, los nuevos contenidos no se podían expresar en el lenguaje artístico anterior, era necesario recurrir a nuevas formas. François-Xavier Guerra, refiriéndose al caso hispanoamericano, señala que la "revolución es una 
mutación cultural: en las ideas, en el imaginario, en los valores, en los comportamientos, en las prácticas, pero también en los lenguajes que los expresan" (49). En este proceso de recambio los patriotas americanos no tuvieron la necesidad de inventarlo todo, podían recurrir al nutrido repertorio de formas que se habían forjado durante la Revolución Francesa, así como a las expresiones liberales de la España del siglo XIX, por mencionar dos contextos que influyen directamente en los procesos de emancipación. Las grandes ciudades hispanoamericanas fueron el escenario para el despliegue de un arte revolucionario que debía, parafraseando a Benedict Anderson, consolidar una comunidad imaginada (23).

A pesar de la relevancia que tendría conocer la concepción acerca del arte en el primer cuarto del siglo XIX, la reflexión en torno a la historia de las ideas en Chile durante el proceso de la emancipación se ha centrado, en el análisis del pensamiento político. Los investigadores han priorizado preguntas en torno a los móviles ideológicos que permitirían explicar la dinámica de los acontecimientos que se suceden desde 1810, dando cuenta así de los fundamentos de la vida republicana.

Uno de los intelectuales estudiados de comienzos del siglo XIX, debido a su decisiva participación en el proceso de independencia, es el jurista nacido en Lima ${ }^{1}$ Juan Egaña Risco. Su intensa actividad política y su amplia producción escrita han dado lugar a una reflexión, aún en desarrollo, tanto desde la historia como desde la filosofía, aunque en menor grado en esta última disciplina.

Pese a ser una figura que ha despertado el interés académico, aún existen aspectos que no han sido indagados minuciosamente; por ejemplo, su visión en torno a la función que la pintura, la música, la escultura, el teatro y la poesía tendrían en la vida pública. Este intelectual ilustrado parece demostrar un gran interés y conocimiento acerca de lo que en la actualidad se llamarían los fenómenos del arte. ${ }^{2}$ El presente trabajo se propone demostrar que Juan Egaña, en sintonía con la filosofía clásica, en particular platónica, concibe al arte como una herramienta eficaz para promover las virtudes cívicas que, según su pensamiento, serían el fundamento del orden social.

El planteamiento anterior requiere tres precisiones. En primer lugar, se debe tener en cuenta que la influencia de los autores clásicos no es privativa de Egaña, las referencias teóricas y simbólicas al mundo grecorromano permitieron a los pensadores ilustrados y a los procesos revolucionarios contar con un sustento de tradición sobre el cual anclarse. En segundo término, se ha de considerar que las concepciones artísticas del jurista pueden haberse forjado al calor de diversas influencias, el propósito del presente artículo es, revelar los alcances de una de ellas. Finalmente, el análisis debe atender al modo cómo

\footnotetext{
${ }^{1}$ Sus antecedentes biográficos se pueden revisar en la publicación de Raúl Silva Castro.

${ }^{2}$ El problema de la evolución del concepto de arte y del uso de la palabra en el lenguaje común y culto supera con mucho los alcances de este trabajo.
} 
Egaña leyó a los clásicos, determinado, sin duda, por las concepciones de su época, por sus experiencias personales y, probablemente, por la lectura de comentaristas.

Las publicaciones dedicadas al pensamiento de Egaña han identificado su amplio conocimiento de los filósofos clásicos, particularmente de Platón; reconociendo que el pensamiento de la antigüedad grecorromana aflora permanentemente en sus textos de contenido político. Hanisch afirmaba en 1964 que la confianza del intelectual en las normas jurídicas como forjadoras de costumbres tendría su origen en el pensamiento platónico (74). Vasco Castillo, por su parte, se hace cargo de la herencia clásica del autor, en los capítulos relativos a la virtud y al modelo de "aristocracia cívica" (21-70, 129-146). No ocurre lo mismo con sus concepciones artísticas. Las ideas de Juan Egaña en este ámbito no han sido trabajadas de forma sistemática, sin embargo, se pueden reconocer algunas observaciones menores que permiten formarse una primera idea acerca de sus convicciones estéticas y de su interés en el tema. Mario Góngora advirtió la minuciosidad con que el jurista describe los rituales republicanos de orientación neoclasicista, reconociendo que la "profusión de alegorías formaban parte de la simbología oficial de la época, particularmente en los períodos revolucionarios" (105106). En fecha reciente se ha intentado atribuir a Egaña la concepción intelectual del monumento efímero erigido para celebrar el 18 de septiembre de 1819, identificando en su iconografía claras alusiones moralistas (Guzmán).

\section{EGAÑA Y LAS FUENTES CLÁSICAS ${ }^{3}$}

Egaña durante su vida demostró una marcada inclinación por el estudio y la lectura, lo que se evidencia en las diversas disciplinas a las que dedicó su empeño, las lenguas que dominaba y la amplia cultura que destilan sus textos. "La erudición es en Egaña una necesidad. Se pasea por todos los autores, por todas las épocas, por todos los pueblos con una soltura admirable" (Hanisch, 25). Estudió filosofía, y además la enseñó en Lima, aunque según su propio testimonio solo enseñó "la más moderna filosofia" (Egaña, Escritos inéditos, 201). Sabe de lógica, metafísica, filosofía natural, psicología, teología natural, ética y filosofia política (Hanisch, 7). A los dieciséis años alcanzó el grado de Maestro de Filosofía y cinco años después los de Maestro en Teología y Leyes, sucesivamente (Hanisch, 12).

La historiografía suele enfatizar el influjo del pensamiento ilustrado en Juan Egaña; concluyendo que su pensamiento sería tributario de autores como Rousseau, Montesquieu y Voltaire (Hanisch, 7). En menor medida se ha

\footnotetext{
${ }^{3}$ Se ha analizado para estos efectos principalmente el Discurso sobre el método de educación nacional, la Constitución Politica del Estado de Chile, el Examen instructivo de la Constitución Politica de Chile, el texto Ocios filosóficos y poéticos en la Quinta de las Delicias, el Código Moral, y El chileno consolado en los presidios, o filosofía de la religión/memoria de mis trabajos $y$ reflexiones, escritas en el padecer y el pensar.
} 
planteado que habría en él influencia del confucionismo (Dougnac), o del conservador Edmund Burke (Collier 268). Definitivamente, en Egaña conviven las ideas modernas de los filósofos ilustrados con formas de entender el mundo y la sociedad propias del pensamiento antiguo, esta dicotomía, ya reconocida por Hanisch, fue un rasgo habitual en muchos intelectuales de finales del siglo XVIII y comienzos del siglo XIX (Hanisch, 23).

Lo cierto es que el jurista chileno leyó y citó a los pensadores griegos y romanos, como se puede constatar de la lectura de sus publicaciones. Este tipo de referencias se podría considerar como un mero ejercicio de retórica, sin embargo, es razonable suponer que en una persona con la vida académica de Egaña manifiestan, al menos en algunos casos, un conocimiento directo de los autores. $^{4}$

\section{LA PRESENCIA DE PLATÓN EN EL PENSAMIENTO DE EGAÑA}

Los vínculos con Platón se pueden identificar en sus reflexiones antropológicas, éticas e incluso jurídicas. La cercanía con Platón se puede ver reflejada claramente en el Código Moral, en Ocios Filosóficos en la Quinta de las Delicias, y en la Constitución del 23. Egaña al igual que Sócrates, Platón y Aristóteles tiene una gran confianza en el poder de las leyes como "agentes de formación moral y cívica". Buenas leyes hacen buenos ciudadanos, provistos de areté. "En la legislación del Estado, se formará el código moral que detalle los deberes del ciudadano en todas las épocas de su edad y en todos los estados de la vida social formándole hábitos, ejercicios, deberes, instrucciones públicas, ritualidades, y placeres, que transformen las leyes en costumbres, y las costumbres en virtudes cívicas y morales" (Art. 249).

Es interesante en este sentido observar el papel fiscalizador que la Constitución del 23 le entrega a los senadores de la República, quienes cada año debían examinar el estado moral de algunas de las provincias en que se dividía administrativamente el territorio; de los diez aspectos a controlar tres de ellos se refieren al comportamiento ciudadano: "Allí examina presencialmente: $1^{\circ} \mathrm{El}$ mérito y servicio de los ciudadanos. $2^{\circ} \mathrm{La}$ moralidad y civismo de las costumbres... $9^{\circ}$ La moralidad religiosa".

Otro rasgo de su pensamiento, en el que se puede reconocer la impronta de su conocimiento de Platón, es la importancia dada a las virtudes cívicas y en especial a la justicia. Para el filósofo griego, como lo expresa en La República, la virtud "política" por excelencia es la justicia, que no es otra cosa que cumplir con lo que el Estado nos

\footnotetext{
${ }^{4}$ El estudio de los clásicos lo pudo realizar en ejemplares de su propiedad o en los que le facilitaran Francisco Tadeo Díez, José Antonio de Rojas o Manuel de Salas, propietarios de extensas bibliotecas. No es posible saber con certeza si en la biblioteca de Egaña se encontraban las obras de Platón o Aristóteles, pues no se conoce el inventario de este conjunto.
} 
manda, es decir, hacer lo que corresponde (Platón, La República 432b). En la Constitución del 23 Egaña acepta la libertad de prensa en la medida que ella contribuya al bien ciudadano: "La imprenta será libre, protegida y premiada en cuanto contribuya a formar la moral, y buenas costumbres (...); a manifestar de un modo fundado las virtudes cívicas y defectos de los funcionarios en ejercicio" (74). En el Código Moral, en el Título Tercero, acerca de la "Educación Nacional", destaca la importancia de la "instrucción pública moral", y "religiosa" (45), por ejemplo, en los "Institutos nacionales"

El estudio de los "documentos morales" debe dirigirse a "contener las pasiones maléficas" y a fomentar "las virtudes cívicas" y resaltar el "celo por la justicia" (Código Moral, 48-49). En atención a esta acentuada preocupación por el cultivo de las virtudes cívicas, la historiografía nacional lo ha caracterizado como un utópico (Góngora). Se trata de una clara coincidencia con Platón, un "idealista", que construye una utopía política, "La República", en donde el gobierno perfecto es ejercido de acuerdo a la virtud, por el "rey-filósofo", que tiene por misión salvaguardar y promover las virtudes ciudadanas. Según Hanisch, "positivamente se conoce que manejó dos textos de utopistas, que son Las Leyes de Platón y la Utopía de Tomás Moro" (Hanisch 73). La convicción de que se debía inculcar el ejercicio de la virtud en los ciudadanos para salvaguardar la sociedad era compartida por casi toda la elite hispanoamericana de comienzos del siglo XIX; sin embargo, "Egaña difirió de sus congéneres permitiendo que esta preocupación especial coloreara su concepción política entera" (Collier, 252).

Otra coincidencia con Platón, no estudiada suficientemente, es su concepción del hombre. La visión de Egaña tiene claros tintes platónicos. Al igual que el filósofo ateniense cree en la separación entre el cuerpo y el alma. El autor establece en su "Ocios Filosóficos", una "distinción absoluta del cuerpo y del espíritu" (42-45), cuando Polemon manifiesta a Philotas: "Decís que yo no os manifiesto al espíritu. Como enteramente distinto del cuerpo. ¿No veis a cada instante la independencia con que obran uno respecto del otro?" (43). Otro rasgo platónico es la carga negativa que le asigna al cuerpo, reflejo de los sentidos. Recordemos que para Platón, como lo expresa en el Crátilo 400c y el Fedón 67e el cuerpo es la "cárcel del alma", pues la mantiene prisionera de los sentidos, impidiéndole ascender hacia el mundo de las ideas. ${ }^{6}$ Esta idea la encontramos en Egaña en su escrito El chileno consolado en los presidios o filosofía de la religión: "Reparad, que a pesar de la ofuscación de nuestra alma que vive sumergida en una materia siempre corriendo a su destrucción, turbada

\footnotetext{
${ }^{5}$ Es interesante, además, consignar que el texto de Egaña está escrito en forma de diálogo, al igual que los platónicos. En su obra los interlocutores son Philotas y Polemon, los cuales, durante seis noches dialogan sobre los más diversos temas.

${ }^{6}$ Véase también La República, Libro VII.
} 
de las pasiones y oprimida de los cuidados, tiene con todo una idea lánguida, pero ingénita de la belleza moral y física" (125).

\section{EGAÑA, EL ARTE Y LAS IDEAS DE PLATÓN}

Una primera muestra de las preocupaciones estéticas de Juan Egaña es la esmerada atención que puso no solo en mejorar las condiciones de su casa en la hacienda de Peñalolén, propiedad que le pertenecía desde 1813, sino en el decoro de la misma. A la ornamentación de la casa con muebles europeos y obras artísticas se sumó la configuración de un parque cuyo trazado aún se puede observar. El énfasis estético puesto por él en las proporciones y armonía del parque nos recuerda a Platón. Se refería a esta casa como la "Quinta de las Delicias", un lugar en que la belleza natural y la producida por el hombre se encontraban armónicamente (Parque Arrieta).

Sin embargo, el disfrute privado, hedonista, de los paisajes y de los objetos artísticos no parece ser en él la perspectiva predominante. Como ya lo constató Collier (256), de la revisión de sus escritos se puede concluir sin dificultad la clara función social que le asigna al arte. Obras como el Código Moral, o La Quinta de las Delicias están jalonadas de numerosos pasajes en los que la música, el teatro, la pintura o la escultura son concebidos como agentes pedagógicos. En el referido Código, redactado por Egaña en 1823, particularmente en la sección dedicada a las fiestas cívicas, se puede encontrar un claro testimonio de la relevancia que le asigna a los asuntos artísticos, entendidos como transmisores de unos determinados valores. Se trata de un cuerpo legal mencionado en la Constitución de 1823, cuyo propósito era precisar una serie de aspectos que la carta fundamental solo enunciaba. Los artículos de este código nunca tuvieron aplicación efectiva, no obstante son de gran interés para conocer los alcances de su pensamiento respecto de la función social del arte. La concepción de esculturas, obras teatrales, himnos y formas arquitectónicas parece haber sido un asunto que despertaba el mayor interés en el jurista, tanto como para incluir en un cuerpo jurídico algunos artículos cuyo único objetivo era precisar las formas de un edificio, dictar las características de una alegoría escultórica o el contenido de una representación dramática. ${ }^{7}$

Egaña, al igual que Platón en Las Leyes (Libros I, II y VII ) y en La República $(410, c)$, está convencido del carácter pedagógico de las manifestaciones artísticas como la música, el teatro y la pintura, las que pueden influir en el carácter de los ciudadanos, conduciéndolos hacia la virtud, tanto en su vida privada como pública. El "arte", según lo que se ha expuesto, es para Egaña un modelador de conductas

\footnotetext{
${ }^{7}$ Otro antecedente que manifiesta su atención por estos temas es el decreto firmado por él y el presidente Freire en diciembre de 1823 con el objeto de prescribir la erección de un arco triunfal para conmemorar la promulgación, ese mismo año, de una nueva constitución (Voionmaa, 81-82). 
cívicas. Él, al igual que Platón, cree que las pasiones humanas desvían a los ciudadanos, especialmente a los jóvenes, de las virtudes cívicas, como por ejemplo, el patriotismo. Por ende, es menester contar con alguna autoridad que vele públicamente por la rectitud de los actos cívicos. Esta autoridad es el magistrado.

El "magistrado de la moralidad", que interviene en "todas las leyes y reglamentos orgánicos que se dictan sobre educación" (Egaña, Código Moral 54), también extiende su jurisdicción sobre el ámbito artístico, evidenciando que para Egaña, en sintonía con el filósofo clásico, la creación dramática, musical o plástica debe estar supeditada a la promoción de las virtudes cívicas. Platón establece, por ejemplo, la necesidad de supervisar la labor de los artistas, especialmente los poetas. Estos últimos están obligados en sus obras a proponer "imágenes" que conduzcan a la virtud (Platón, La República, Libro X 595 y ss.). Imitar lo malicioso e intemperante es pernicioso, debido a que puede generar en los jóvenes una adhesión al vicio, corrompiendo de esa manera el alma del joven. Egaña manifiesta esta idea cuando establece, por ejemplo, que "los maestros públicos de canto serán obligados a acomodar sus cantares con letras análogas a los objetos expuestos" (Código Moral, 82-83), es decir, que conduzcan a las virtudes privadas y públicas.

Como ya se ha indicado, las ideas clásicas conviven en Egaña con las concepciones de los pensadores ilustrados. Se puede afirmar que esta inspiración es manifiesta en sus reflexiones acerca de la política, pero no en relación con el arte, realidad en que resulta difícil establecer un vínculo entre Egaña y los filósofos del siglo XVIII. No se debe desconocer la importancia que le atribuyen algunos ilustrados al rol social del arte, y al compromiso "sociopolítico" del artista, pero esto no es identificable sin más al rol pedagógico que le atribuye Egaña al arte. Al igual que en Platón, el énfasis del jurista está más puesto en la función de la obra y no en el artista. Es más, el rol que le asigna Egaña al arte es muy diferente al de Rousseau, pues para este, como lo establece en su famoso discurso acerca de las ciencias y las artes, estas cumplen una función "ideológica", de "ocultamiento" de la realidad, pues cubren con guirnaldas de flores las cadenas del hombre, que no es más que un esclavo civilizado, más aún, son producto del lujo, que a su vez ha nacido de las riquezas. En el texto comentado, Rousseau alude a Platón precisamente para celebrar la expulsión de los artistas. Más aún, para el ginebrino, las ciencias y las artes deben su nacimiento a nuestros vicios. En suma, Rousseau concluye que las artes corrompen las costumbres. Tampoco se puede afirmar que Montesquieu otorgue un rol pedagógico al arte. Para este autor las bellas artes tendrían como propósito otorgar placer a las personas. Luego, es evidente que Egaña no puede haberse sustentado en las ideas de Rousseau y difícilmente en las de Montesquieu.

La posibilidad de promover eficazmente el cultivo de las virtudes públicas por medio de la legislación y el arte es uno de los aspectos centrales en el pensamiento de 
Platón y en la reflexión y praxis política de Egaña. Dicha concepción era compartida por gran parte de la elite ilustrada americana y también europea; la soberanía popular ejercida por ciudadanos incultos y viciosos entrañaba el fin de la República, por tanto, el pueblo debía ser instruido por medio de la "legislación..., la elaboración de la memoria histórica nacional, la educación escolar y la mise en scène de rituales, símbolos e iconografia" (Ortemberg, 701).

Un primer aspecto que podría tenerse en cuenta es que Egaña lee a Platón desde la perspectiva de una persona que ha sido contemporáneo a la Revolución Francesa; debe recordarse que para 1789 tenía veintiún años. Es probable que, como a muchos hispanoamericanos, los excesos y la violencia que sobrevinieron durante este proceso político fuesen una permanente señal de advertencia frente a los peligros de una revolución liberal que no se cimentara en una moral cívica aceptada y cultivada por el grueso de la población. Las perspectivas platónicas sobre este punto se podían leer a finales del siglo XVIII o comienzos del siglo XIX como auténticas profecías; es probable que algo así le ocurriera a Egaña, identificando en los textos del autor griego un conjunto de ideas perfectamente funcionales a las circunstancias políticas de la emancipación de Hispanoamérica.

Otro aspecto especialmente significativo sería la relevancia que Egaña le asigna, como se verá a continuación, a la fiesta como articulador de los distintos mensajes moralizantes. La música, la retórica, las esculturas emblemáticas y demás elementos cobran verdadero sentido pedagógico en los fastos republicanos que el jurista concibe. Se trata de una idea ajena a los textos de Platón, para el griego todas las artes deben inculcar normas morales, pero nunca señala que estas deben conjugarse en el contexto de la fiesta; se trataría de una idea de Egaña, recogida, tal vez, de sus lecturas de Confucio o de su experiencia con los fastos coloniales.

\section{EL TEATRO Y LA MÚSICA}

Egaña establece en el artículo 288 del Código Moral la realización de la "Fiesta de la Justicia y Moralidad Pública" (127), cuyo principal objetivo es la proclamación de "las virtudes públicas que consolidan el buen orden social y la moralidad pública" (86). En este contexto, establece en el artículo 175: "Los teatros y espectáculos dramáticos serán una escuela de moralidad y virtudes cívicas", e introduce nuevamente la idea platónica de la "fiscalización": "Toda representación pública debe revisarse y aprobarse por los magistrados de moralidad" (81-82).

Platón concibe la música como el arte educador por excelencia, y que al ser la "más elevada, es por lo mismo la que exige más cuidado y atención" (Platón, Las Leyes, Libro II). Ella llega al alma mediante los sonidos, y nos inspira el gusto por las virtudes. En virtud de ello, los componentes musicales no deben transmitir otra cosa que no sea aquello que acerca a la virtud. En vistas a este fin, establece tres elementos: las palabras, la armonía y el ritmo. Es decir, bajo el concepto de música se incluye 
todo lo que concierne a las musas, a saber: la literatura, las artes, la danza y el canto. Para el filósofo griego, "la buena educación consiste en saber cantar bien y danzar bien" (Platón, Las Leyes, Libro II). ${ }^{8}$ Las palabras, deben ser imitaciones de las cualidades que conviene adquirir como la templanza, o la magnanimidad. No se debe imitar el vicio, pues la educación musical comienza en la niñez y se prolonga hasta la juventud, creando un hábito o una especie de "segunda naturaleza" que forma el cuerpo, la voz y el pensamiento. La música es, entonces, la parte esencial de la educación debido a que el ritmo y la armonía son especialmente apropiados para adentrarse en el alma y conmoverla. La música no debe sino conducir a la virtud, es decir, a la adhesión a lo bueno, bello y verdadero. "Toda figura y toda melodía que expresan las buenas cualidades del alma o del cuerpo, sea en sí mismas, sea en su imagen, son bellas" (Platón, Las Leyes, Libro II). Estas ideas Egaña las recoge de la siguiente manera: "la música en que se expresa los himnos y cantares clásicos nacionales o religiosos ha de ser precisamente magestuosa, simple y patética, a propósito para elevar y penetrar el corazón" (Código Moral, 83-84). Al igual que Platón (Las Leyes, 668b), para Egaña el rol de la música en las fiestas y en el ámbito educativo no debe ser el despertar en el oyente una sensación placentera, sino producir o acrecentar el deseo de actuar rectamente. En su obra Ocios filosóficos y poéticos, en el capítulo titulado "Progresos que faltan al género humano" dedica un par de páginas a estudiar los "efectos morales y físicos que pueden producirse con la música". (10). Allí afirma:

"La música indica, que la moralidad; el manejo de las pasiones; la verdadera idea de lo bello, y de las proporciones; las costumbres virtuosas y delicadas, un carácter noble, tierno, sublime y generoso, deben ponerse bajo su influencia; y que algún día dirigirá la educación, arreglará el temperamento, servirá de auxilio en muchas enfermedades, y calmará o animará las pasiones, cuyos ensayos suelen experimentarse algunas veces, y se vieron más efectivos en las épocas de Saúl, de Alejandro, de los antiguos griegos, y aun ven hoy en la corte de los incas" (102).

\section{MONUMENTOS: ARQUITECTURA Y ESCULTURA}

Uno de los aspectos que parece preocupar especialmente a Egaña es la erección de monumentos efímeros o permanentes, estructuras en torno a las cuales debieran desarrollarse parte de los actos festivos. Se trata de soportes arquitectónicos y esculturas concebidas con un claro propósito didáctico. De

\footnotetext{
${ }^{8}$ Siguiendo con su espíritu platónico, Egaña no descuida la importancia de la gimnástica en la formación del joven. Recordemos que para Platón tanto la música como la gimnasia educan el alma. Esta última educa el lado "fogoso" (thymoeidés) del hombre y si se combina con la música, que cultiva la dulzura, produce, en lugar de fuerza bruta, valentía (Platón, La República, 410b).
} 
alguna manera, con nuevas formas y contenidos, se da continuidad a un lenguaje habitual en la Hispanoamérica colonial. ${ }^{9}$

De especial interés resulta el monumento para la fiesta de la moralidad o batalla de Maipú, descrito en el Código Moral. ${ }^{10}$ También es posible atribuirle la concepción general de un complejo montaje arquitectónico y escultórico que se levantó para celebrar el 18 de septiembre de 1819 (Guzmán, Representaciones del Paraíso, 23-28). "En efecto, un artículo del periódico El Telégrafo, publicado el 9 de octubre de ese año, junto con reseñar el desarrollo de los festejos entrega una detallada caracterización de la estructura que la Municipalidad de Santiago levantó en la Plaza de Armas, espacio privilegiado de las fiestas cívicas" (Guzmán, "Un monumento efímero"). El monumento consideraba la erección, en el centro de la estructura de cuatro columnas dóricas que sostenían las alegorías escultóricas de la justicia, la fortaleza, la prudencia y la templanza, manifestando que para Egaña el ejercicio de las virtudes cardinales es el corazón y fundamento de la vida social. Se debe recordar que para Platón estas cuatro virtudes son fundamentales para la buena vida en la Polis: "En el orden de los bienes divinos, el primero es la prudencia, después viene la templanza y de la mezcla de estas dos virtudes y de la fortaleza nace la justicia que ocupa el tercer lugar, la fortaleza es la cuarta" (Las Leyes, Libro I ).

\section{CARACTERÍSTICAS GENERALES DE LAS FIESTAS CÍVICAS}

Egaña concibe a la música, la poesía, las representaciones y las esculturas confluyendo en la fiesta cívica; instancia de quiebre de la cotidianeidad en la que se destacaban las virtudes y los generosos servicios prestados a la nación por los beneméritos, con el objeto de que los ciudadanos los admiraran y se sintieran impulsados a imitar sus acciones. Se trata, en parte, de la lógica, tan característica de la cultura barroca, de usar la fiesta para conseguir objetivos políticos. Se recoge esa práctica dotándola de nuevas formas y contenidos (Peralta, 89; Cruz, 296-307).

El Código Moral dedica diecinueve páginas a normar el desarrollo de las fiestas cívicas, la extensión del apartado es una clara manifestación del interés del autor por todo lo relativo a la conmemoración de los hitos históricos. En la concepción de estos fastos republicanos destacan cuatro rasgos fundamentales. En primer lugar, al igual que Platón, considera indispensable normar su desarrollo, función que se entrega al Senado, pues la improvisación y el desorden de los carnavales se encuentran en las antípodas del espíritu que debe empapar la nueva fiesta. Platón asigna al legislador la función de "hacer reglamentos y leyes a propósito

\footnotetext{
${ }^{9}$ Un ejemplo colombiano, anterior a la Independencia, de esta evolución de los monumentos efímeros se puede ver en Gutiérrez, 70-71.

${ }^{10}$ En la plaza, sobre una gran tarima, se ordena construir un trono con la estatua de la justicia, en cuyas gradas se debían ubicar las representaciones de Isaac, Abraham, Bruto, Leonidas, Arístides y Sócrates; modelos de la sumisión, el respeto y la integridad (Egaña; Código Moral 128-135).
} 
de las fiestas" (Las Leyes, Libro VIII, 828a), y si fuese necesario aplicar también censura (Las Leyes, Libro VII, 817ab).

En segundo término, se pone énfasis en la necesidad de dotar a las ceremonias de la solemnidad y la suntuosidad requeridas para exteriorizar la importancia de los hechos que se conmemoran. Una tercera característica es la obligatoriedad para los ciudadanos de participar y para las regiones de plegarse a los ceremoniales establecidos en la Constitución y regulados por el Senado. Un último rasgo, especialmente relevante, es la centralidad que se otorga a la premiación de los ciudadanos virtuosos o beneméritos de la República, cuyo ejemplo debe ser destacado en estas ocasiones para aprovechamiento de los demás ciudadanos.

La "pompa exterior" descansa en aspectos particulares que Egaña se encarga de establecer: el adorno de las calles, los arcos florales, las vestimentas de los participantes, banderas y guirnaldas, las iluminaciones; detalles que no se consideran irrelevantes, de ellos depende la primera impresión que los ciudadanos se llevaron de la ceremonia festiva. La falta de aseo, los trajes deslucidos y la falta de ornato atentarían contra el propósito final: que los ciudadanos se identifiquen con los valores republicanos.

En este sentido, es evidente que el núcleo de toda esta liturgia civil concebida por Egaña es la exaltación de las virtudes cívicas. Los elogios de los beneméritos, la entrega de medallas y coronas, el himno de la justicia y la moralidad pública, los elocuentes discursos, los ejercicios militares y las representaciones dramáticas cargadas de moralejas eran herramientas para presentar el beneficio social de la corrección y la honestidad. Es bien probable que el modelo más inmediato para esta idea lo haya encontrado en las formas festivas que surgen en el contexto de la Revolución Francesa (Ozouf, 335). ${ }^{11}$

En sintonía con Platón no olvida el carácter recreativo de las fiestas, pero no sería esa, a su juicio, su función principal. Para el autor chileno las fastos civiles están "destinadas a premiar la virtud y los servicios" (Egaña, Código Moral 62). A dichas fiestas deben acudir no solo los adultos, sino los jóvenes, pues, la contemplación de las virtudes cívicas expuestas en la fiesta, no solo ayudará al joven a alejarlo del vicio, sino además a exaltar, entre otras cosas, el "amor a la patria".

\section{CONCLUSIÓN}

Al tenor de lo expuesto en estas páginas, se puede afirmar que este pensador considerado por la historiografía como un ecléctico, al menos en lo que se refiere al rol de las artes en la sociedad es tributario de la filosofía clásica, especialmente de Platón. Tanto para el filósofo griego como para Egaña las palabras, la armonía, el

\footnotetext{
${ }^{11}$ Un ejemplo americano de esta influencia se puede encontrar en Burucúa, Jáuregui, Malosetti y Munilla; así como en: Garavaglia.
} 
ritmo de la música (melodía) y los objetos bellos (esculturas, templos, pinturas, etc.) deben colaborar a forjar los buenos hábitos de los ciudadanos. El intelectual chileno parece confiar en que los edificios, los himnos patrióticos y las alegorías escultóricas serán eficaces pedagogos, promotores de las virtudes cívicas. De este modo, el arte sería una suerte de "campo de batalla" entre el vicio y la virtud, y un buen gobernante sabe, por tanto, que un descuido en estos aspectos puede acarrear nefastas consecuencias. De allí su preocupación por la "fiscalización" de las expresiones artísticas por medoo de los magistrados de la moralidad.

La originalidad de Egaña se encuentra en la síntesis conceptual y práctica que le lleva a concebir la fiesta como una instancia totalizadora en la que deben confluir las diversas manifestaciones de las artes para conseguir el objetivo deseado. La adecuada articulación de música, discurso, teatro, arquitectura, esculturas, pinturas y ceremonias permite dar vida a una performance que fustiga el vicio y exalta la virtud. En consecuencia, el arte no puede renunciar a promover las ideas de bien, verdad y belleza, dicho de otro modo, no debe eludir su carácter pedagógico.

Universidad Adolfo Ibáñez*

Facultad de Artes Liberales

Departamento de Historia Avda. Diagonal las Torres 2640, Peñalolén, Santiago (Chile) fernando.guzman@uai.cl

Universidad Adolfo Ibáñez**

Facultad de Artes Liberales

Departamento de Filosofia

Avda. Diagonal las Torres 2640, Peñalolén, Santiago (Chile)

eyanezr@uai.cl 
La recepción de los clásicos en las concepciones de Juan Egaña

\section{OBRAS CITADAS}

Anderson, Benedict. Comunidades imaginadas. Reflexiones sobre el origen y la difusión del nacionalismo. México: F.C.E., 1993.

Burucúa, José Emilio; Jáuregui, Marta; Malosetti, Laura; Munilla, María Lía. "Influencia de los tipos iconográficos de la revolución francesa en los países del plata". Cahiers des Amériques Latines, L'Amérique Latine face à la révolution, 10. 1990:147-157.

Castillo, Vasco. La creación de la República. La filosofia pública en Chile 1810-1830. Santiago: LOM Ediciones, 2009.

Collier, Simon. Ideas and Politics of Chilean Independence 1808-1833. Cambridge: Cambridge University Press, 1967.

Cruz, Isabel. La Fiesta, metamorfosis de lo cotidiano. Santiago: Ediciones Universidad Católica de Chile, 1995.

Dougnac, Antonio. "El pensamiento confuciano y el jurista Juan Egaña (17681836)", en Revista de Estudios Histórico Jurídicos 20. 1998:143-193.

Egaña, Juan. Escritos inéditos y dispersos. Santiago: Imprenta Universitaria, 1949.

------ "Código Moral". Colección de algunos escritos políticos, morales, poéticos y filosóficos. Burdeos: Imprenta de Laplace y Beaume, 1831.

------ Ocios filosóficos y poéticos en la quinta de las delicias. Londres: Impreso por D. Manuel Calero, 1829.

------ El chileno consolado en los presidios, o, Filosofía de la religión /memoria de mis trabajos y reflexiones, escritas en el padecer y pensar. Londres: Imprenta Española de M. Calero, 1826.

------ "Constitución Política del Estado de Chile". Colección de algunos escritos políticos, morales, poéticos y filosóficos. Londres: 1826-1830.

Discurso sobre el método de educación nacional. Fondos Varios, Archivo Nacional. Vol. 796.

Garavaglia, Juan Carlos. Construir El Estado, Inventar La Nación. El Río de La Plata. S XVIII - XIX. Buenos Aires: Prometeo Libros, 2007.

Góngora, Mario. "El rasgo utópico en el pensamiento de Juan Egaña". Anales de la Universidad de Chile 129. 1964:93-119.

Guerra, Francois-Xavier. Modernidad e independencias, ensayos sobre las revoluciones hispánicas. Madrid: Fundación Studium y Ediciones Encuentro, 2009.

Gutiérrez, Ramón; Gutiérrez, Rodrigo. América y España, imágenes para una historia. Madrid: Fundación Mapfre, 2006.

Guzmán, Fernando. "Un monumento efímero para celebrar la Independencia". Guzmán, Fernando y Martínez Juan Manuel (Editores), Arte americano e 
Independencia. Nuevas Iconografías. Quintas Jornadas de Historia del Arte, 2010:23-28.

Guzmán, Fernando. "El pensamiento de Juan Egaña y el monumento erigido para celebrar el 18 de septiembre de 1819". Atenea (Artículo aceptado).

Hanisch, Walter, S.I. "La filosofía de don Juan Egaña". Historia 3. 1964:164310 .

Ortemberg, Pablo. "Algunas reflexiones sobre el derrotero social de la simbología republicana en tres casos latinoamericanos. La construcción de las nuevas identidades políticas en el siglo XIX y la lucha por la legitimidad", Revista de Indias, 2004, vol LXIV, núm 232, 697-720.

Hobsbawm, Eric. La era de la revolución. 1789-1848. Barcelona: Editorial Crítica, 2005.

Montesquieu, Charles Louis de. Ensayo sobre el gusto. Espasa-Calpe. Buenos Aires, 1948.

Ozouf, Mona. La fête révolutionnaire: 1789-1799. París: Gallimard, 1976.

Parque Arrieta. Monumento Histórico Nacional. Santiago, Universidad Internacional Sek, 1995.

Peralta, Paulina. Chile tiene fiesta. El origen del 18 de septiembre (1810-1937). Santiago, Chile: LOM Ediciones, 2007.

Platón. Crátilo. Madrid: Editorial Gredos, 1999.

------ La República. Madrid: Editorial Gredos, 1998.

------ Las Leyes. Madrid: Ediciones Ibéricas, 1960.

Salinas, Carlos. "La biblioteca de don Mariano Egaña, con especial referencia a sus libros de derecho". Revista de Estudios HistóricoJurídicos 7, 1982.

Rousseau, Jean Jacques. El contrato social, o, principios de derecho político. Discurso sobre las ciencias y las artes. Discurso sobre el origen de la desigualdad. México: Porrúa, 1982.

Silva Castro, Raúl. Egaña en la Patria Vieja 1810-1814. Santiago: Editorial Andrés Bello, 1959.

Silva Castro, Raúl. Juan Egaña: (1768-1836). Santiago de Chile: Editorial Andrés Bello, 1969.

Smith, Anthony. Nacionalismo: teoría, ideología, historia. Madrid: Alianza Editorial, 2002.

Voionmaa, Liisa Flora. Escultura Pública. Del monumento conmemorativo a la escultura pública. Santiago 1792-2004. Santiago de Chile: Ocho Libros Editores, 2004. 